\title{
QUANTIFICAÇÃO DE SERAPILHEIRA E DE NUTRIENTES - FLORESTA OMBRÓFILA MISTA MONTANA - PARANÁ
}

\author{
Litter and Nutrients Quantification - "Ombrofila Mista Montana" Forest- Parana
}

\author{
Marcos Vinicius Winckler Caldeira \\ Prof. Dr. Departamento de Engenharia Florestal/Centro de Ciências Tecnológicas/FURB \\ Universidade Regional de Blumenau, Blumenau - SC. e-mail: caldeiramv@yahoo.com.br
}

Renato Marques

Prof. Dr. Departamento de Solos e Engenharia Agrícola - UFPR, Curitiba - PR: e-mail. rmarques@ufpr.br

Ronaldo Viana Soares

Prof. Dr. Departamento de Ciências Florestais da Universidade Federal do Paraná, Centro de Ciências Florestais e da Madeira/UFPR, Curitiba - PR. e-mail: rvsoares@floresta.ufpr.br

\section{Rafaelo Balbinot}

Prof. M.Sc. Departamento de Engenharia Ambiental/Setor de Ciências Agrárias e Ambientais. Universidade Estadual do Centro-Oeste (UNICENTRO), Câmpus Irati, Irati - PR. e-mail: rbalbinot@yahoo.com.br

\section{Resumo}

O objetivo desse estudo foi quantificar a produção de serapilheira acumulada e o conteúdo de nutrientes e de carbono orgânico na Floresta Ombrófila Mista Montana, General Carneiro, PR. A coleta de serapilheira acumulada foi realizada durante o primeiro semestre de 2001 (janeiro a julho), utilizando 18 unidades amostrais primárias (UAPs) $(12 \times 12 \mathrm{~m})$. Em cada UAP, com o auxílio de um gabarito de metal de 0,25 m x 0,25 m, foi coletado o material de estudo de forma aleatória, com oito (08) repetições por UAP. A Floresta Ombrófila Mista Montana acumulou em média 7,99 $\mathrm{Mg}^{-h^{-1}}$ de serapilheira. Observou-se que a serapilheira foi uma importante via de transferência de carbono orgânico, de macronutrientes (N, K e Ca) e micronutrientes (Fe, Mn e Zn) para o solo.

Palavras-chave: Carbono orgânico; Transferência de nutrientes e serapilheira acumulada; Relação C/N.

\begin{abstract}
The aim of this study was to quantify the production of accumulated litter and the nutrients content and organic carbon in an "Ombrofila Mista Montana" Forest, General Carneiro, PR. The sampling of the accumulated litter was realized during the first semester of 2001 (January to July), using 18 primary sampling units (UAPs) $(12 \times 12 \mathrm{~m})$. It was used a $0.25 \mathrm{~m} \times 0.25 \mathrm{~m}$ metallic accessory to collect the study material on each UAP, in a randomize way, with 8 replications per UAP. The average accumulated litter in

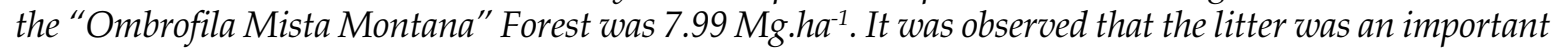
way to transfer organic carbon, macronutrients ( $\mathrm{N}, \mathrm{Ke} \mathrm{Ca}$ ) and micronutrients ( $\mathrm{Fe}, \mathrm{Mn}$ e $\mathrm{Zn}$ ) to the soil.
\end{abstract}

Keywords: Organic carbon; Macronutrients transfer and accumulated litter; C/N relation. 


\section{INTRODUÇÃO}

Em todas as tipologias florestais, sabe-se que a produção de serapilheira representa o primeiro estágio de transferência de nutrientes e energia da vegetação para o solo, pois a maior parte dos nutrientes absorvidos pelas plantas retorna ao piso florestal por meio da queda de serapilheira ou lavagem foliar (CARPANEZZI, 1997).

Os estudos sobre a produção de serapilheira em diversas florestas do mundo têm sido realizados por vários motivos (PROCTOR, 1983):

a) prover um índice de produção, pois pode ser considerado como um indicador do nível mínimo de produtividade primária líquida das florestas (BRAY; GORHAM, 1964);

b) prover informações sobre a taxa de decomposição, quando combinada com a quantificação de serapilheira acumulada no piso florestal (FLOSS; CALDATO; BOHNER, 1999);

c) prover informações fenológicas das árvores (TALORA; MORELLATO, 2000);

d) quantificar uma importante via dos ciclos de nutrientes e indicar a eficiência destes ciclos (VITOUSEK, 1984).

A serapilheira acumulada desempenha um papel essencial no crescimento das plantas, pois influencia nas propriedades físicas, biológicas e químicas dos solos, bem como aumenta a capacidade de troca catiônica (CTC) do solo (SYERS; CRASWEL, 1995; GARAY; ANDRADEDE; KINDEL, 2001). Além disso, o material acumulado permite a existência de uma grande variedade de nichos para a mesofauna e microrganismo, bem como fonte de colóides para o solo (SANTOS, 1989).

Nesse sentido, a serapilheira acumulada exerce, também, funções de isolante térmico (melhoras as condições térmicas dos horizontes mais profundos) e retentor de água; atua como atenuador de efeitos erosivos, bem como tem grande efeito hidrológico, funcionando principalmente como filtro e armazenador de água proveniente da atmosfera que penetra no solo (SANTOS, 1989).

O acúmulo de serapilheira varia em função da procedência, da espécie, da cobertura florestal, do estágio sucessional, da idade, da época da coleta, do tipo de floresta e do local.

Além dos fatores citados acima, outros, como condições edafoclimáticas e regime hídrico, condições climáticas, sítio, sub-bosque, manejo silvicultural, proporção de copa, bem como taxa de decomposição e distúrbios naturais como fogo e ataque de insetos ou artificiais como remoção da serapilheira e cultivos, ocorridos na floresta ou no povoamento, também influenciam no acúmulo de serapilheira.

A quantidade de nutrientes que chega ao piso florestal, presente na serapilheira, depende de dois grandes fatores: o primeiro refere-se à produção de folhas, a qual é influenciada por vários fatores, e o segundo são os teores dos nutrientes presentes nas folhas, também sujeitos a muitas influências (CARPANEZZI, 1997).

As folhas da serapilheira são responsáveis pelo retorno da maior quantidade de nutrientes ao solo. Essa contribuição deve-se muito mais às quantidades de folhas depositadas do que aos teores dos elementos. Os teores de $\mathrm{N}$ e P são superiores na fração miscelânea que, no entanto, representa uma pequena proporção da serapilheira ( 7 a $25 \%$ do peso). Nessa fração, estão inclusos frutos, flores, pequenos insetos e excrementos, que podem ser os responsáveis pelo elevado teor desses elementos (WISNIEWSKI et al., 1997).

O objetivo desse estudo foi quantificar a produção de serapilheira acumulada e o conteúdo de nutrientes e de carbono orgânico na Floresta Ombrófila Mista Montana, General Carneiro/PR. 


\section{MATERIAIS E MÉTODOS}

O estudo foi realizado em uma propriedade das Indústrias Pedro N. Pizzatto, localizada no município de General Carneiro, Paraná, localizado nas coordenadas geográficas $26^{\circ} 4300$ "latitude S e $51^{\circ}$ 24 35" longitude W de Greenwich (FIGURA 1), com altitude aproximada de 1000 m s.n.m. (PARANÁ, 1987). A área da fazenda onde foi desenvolvido o trabalho é de aproximadamente de 4.570 ha.

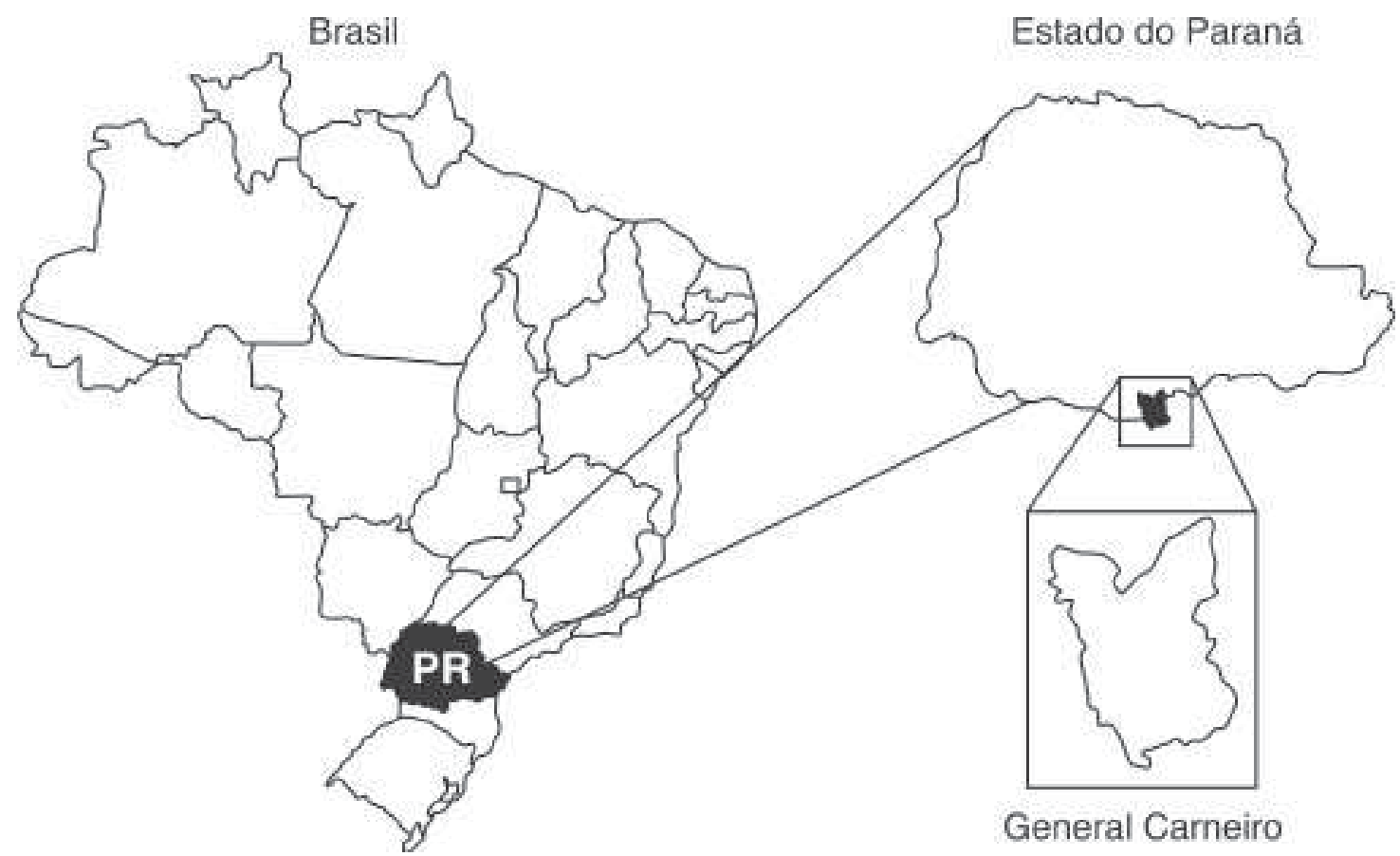

FIGURA 1 - Localização geográfica do municipío de General Carneiro Figure 1 - Geographical localization of General Carneiro municipality

Pela classificação de Köeppen, o clima da região é caracterizado como Subtropical Úmido Mesotérmico (Cfb), ou seja, temperado com verões frescos e invernos, com ocorrência de geadas severas, sem estação seca. A média das temperaturas do mês mais quente é inferior a $22^{\circ} \mathrm{C}$ e a do mês mais frio é superior a $18^{\circ} \mathrm{C}$ (PARANÁ, 1987; IAPAR, 1994). Para Camargo (1998), o clima da região pode ser considerado como Temperado Semi-Úmido de Altitude.

Em relação ao relevo, General Carneiro apresenta 20\% de topografia plana, 65\% de topografia ondulada e $15 \%$ de topografia montanhosa. Nessa região, as ordens de solos predominantes são os Neossolos Litólicos, Cambissolos e Argissolos (BOLETIM DE PESQUISA, 1984; PARANÁ, 1987).

Conforme a classificação do IBGE (1992), a formação florestal original da área de estudo é classificada como Floresta Ombrófila Mista Montana. Contudo, devido às diversas atividades antrópicas, a vegetação se encontra em diferentes estágios sucessionais.

Na Figura 2 pode-se observar o uso do solo da área de estudo, com as respectivas localizações das unidades amostrais. 
No primeiro semestre de 2001, o Laboratório de Inventário Florestal/UFPR realizou o inventário florestal, utilizando o método de amostragem de área fixa e o processo sistemático, no qual foram locadas e medidas 70 unidades amostrais (UAs) de $25 \mathrm{~m}$ x $100 \mathrm{~m}$, numeradas de 1 a 70 (FIGURA 2).

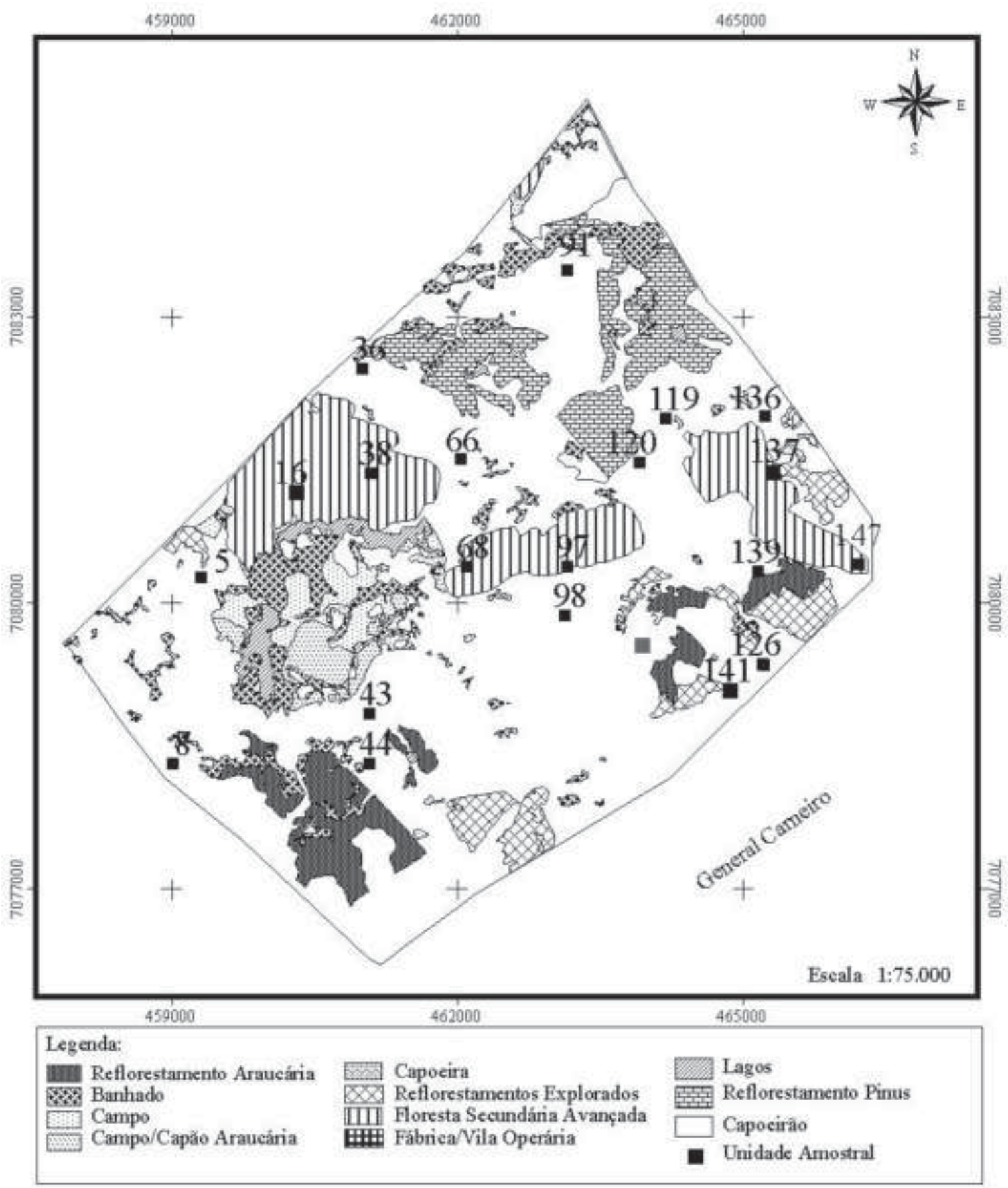

FIGURA 2 - Uso do solo e localização das unidades amostrais (UAs) na Floresta Ombrófila Mista Montana (PR)

Figure 2 - Soil use and the sampling units localization (UAs) in the "Ombrofila Mista Montana" Forest (PR) 
Para as coletas da serapilheira acumulada, foram utilizadas 18 unidades amostrais primárias (UAPs) (12 x $12 \mathrm{~m}$ ) (FIGURA 3). Em cada UAP, com o auxílio de um gabarito de metal de 0,25 m x 0,25 $\mathrm{m}$, foi coletado o material de estudo de forma aleatória, com oito (08) repetições por UAP.

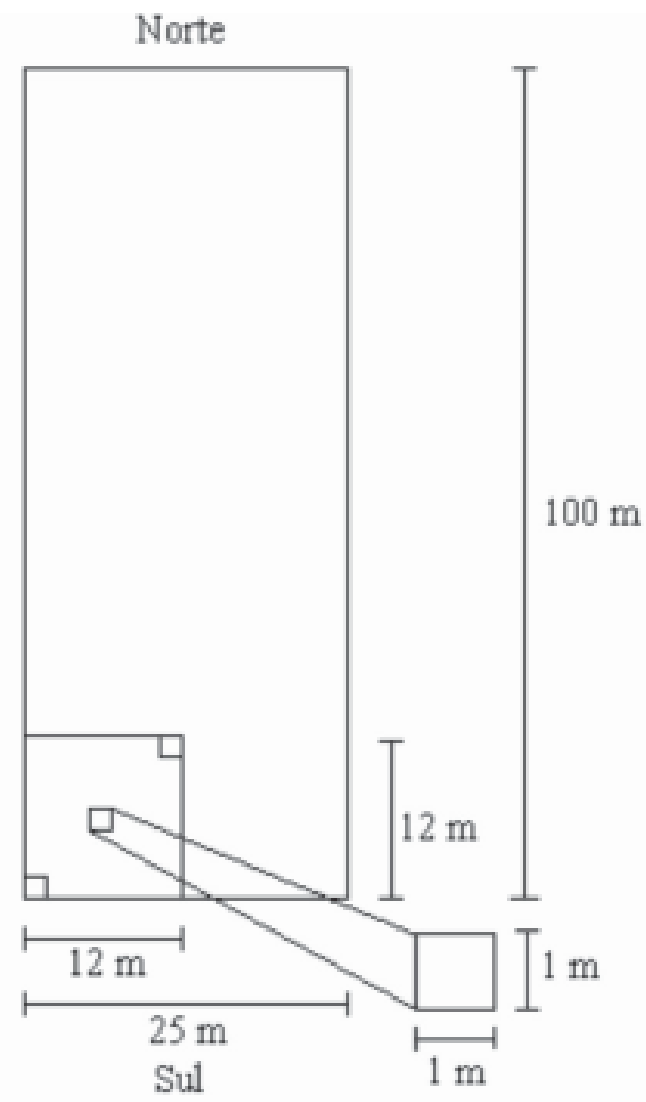

FIGURA 3 - Croqui da instalação das unidades amostrais

Figure 3 - Sampling units croquis

Para a determinação do peso seco das amostras de serapilheira acumulada, essas foram colocadas em sacos de papel, secas em estufa de circulação e renovação de ar a $65^{\circ} \mathrm{C}$ até alcançar massa seca constante e aferidas em balança de precisão $(0,01 \mathrm{~g})$. A quantidade de serapilheira acumulada encontrada no gabarito de metal $\left(\mathrm{g} / 0,0625 \mathrm{~m}^{2}\right)$ foi estimada para megagrama por unidade amostral primária (Mg.UAP $\left.{ }^{-1}\right)$.

As amostras de serapilheira acumulada foram colocadas em sacos de papel, secas em estufa de circulação e renovação de ar a $65^{\circ} \mathrm{C}$ até alcançar massa seca constante e em seguida triturada em moinho do tipo Wiley, passadas em peneiras de malha 1,0 $\mathrm{mm}$ (20 mesh) e armazenadas em frascos de vidros para subseqüente análise química (TEDESCO et al., 1995; MIYAZAWA et al., 1999). 
O tecido vegetal para a determinação de N, P, S, K, Ca, Mg e carbono orgânico foi submetido à digestão úmida. As análises de $\mathrm{N}$ foram feitas por titulação. $\mathrm{O} \mathrm{N}$ foi determinado pelo método Kjeldahl, chamado também de digestão sulfúrica usando o destilador de nitrogênio. As amostras de $\mathrm{K}$ foram lidas no fotômetro de chama e as amostras de P e S foram lidas no espectrofotômetro visível (VIS). No espectrofotômetro de absorção atômica (EAA), foram lidas as amostras de Ca e Mg. O carbono orgânico foi determinado pelo método Walkley-Black (TEDESCO et al., 1995; MIYAZAWA et al., 1999).

Os extratos de tecido vegetal de $\mathrm{Cu}, \mathrm{Zn}, \mathrm{Fe}$ e $\mathrm{Mn}$ foram obtidos por digestão úmida solução nítrica-perclórica. As análises de B feitas por digestão seca. No espectrofotômetro de absorção atômica (EAA) foram determinados os teores de $\mathrm{Cu}, \mathrm{Zn}, \mathrm{Fe}$ e $\mathrm{Mn}$. O teor de Boro foi determinado no espectrofotômetro visível (VIS) (TEDESCO et al., 1995; MIYAZAWA et al., 1999).

Para a serapilheira acumulada nas 18 UAPs, foram calculadas as seguintes estatísticas: média (x); variância $\left(\mathrm{s}^{2}\right)$; desvio-padrão (s); erro-padrão $\left(\mathrm{s}_{\mathrm{x}}\right)$; intervalo de confiança a $5 \%$ de probabilidade (IC $5 \%$ e coeficiente de variação em percentagem (CV\%). Para determinar a intensidade amostral necessária na coleta de serapilheira acumulada, visando a uma estimativa da média com $10 \%$ e $20 \%$ de erro, a $95 \%$ de probabilidade, foi utilizada a fórmula, para população infinita em função da variância, seguindo os procedimentos descritos por Stein (STEEL; TORRIE, 1960):

$$
n=\frac{t^{2} \cdot s^{2}}{E^{2}} \quad \text { onde: } \mathrm{n}=\text { número de amostras }
$$

$\mathrm{t}^{2}=$ valor tabelar de " $\mathrm{t}$ " a $5 \%$ de probabilidade e 17 graus de liberdade

$\mathrm{s}^{2}=$ estimativa da variância

$\mathrm{E}^{2}=$ erro previamente especificado (10 e $20 \%$ da média)

Com o objetivo de determinar se existe diferença na serapilheira acumulada entre as 18 UAPs, cada uma foi considerada como um tratamento em um delineamento inteiramente casualizado, com as oito amostras de cada unidade consideradas como repetição. As médias das UAPs foram comparadas pelo teste de Student Neuman Keul's - SNK a 5\% de probabilidade.

\section{RESULTADOS E DISCUSSÃO}

\section{Biomassa da serapilheira acumulada}

As menores quantidades de serapilheira acumulada foram encontradas nas UAPs 120 e 126 e a maior quantidade na UAP 147. A Tabela 1 também mostra a relação C/N média da floresta em estudo e a relação em cada UAP. As maiores relações de C/N (decomposição lenta) foram observadas nas UAPs 139 e 66 e as menores relações (decomposição rápida) na unidade 91. 
TABELA 1 - Serapilheira acumulada e relação C/N por unidade amostral primária (UAP), General Carneiro (PR)

Table 1 - Accumulated litter and C/N relation per primary sampling unit (UAP), General Carneiro (PR)

\begin{tabular}{|c|c|c|c|c|c|c|}
\hline \multirow{2}{*}{$\frac{U A P}{120}$} & \multicolumn{4}{|c|}{$\begin{array}{c}\text { Média da serapilheira acumulada } \\
\left(\mathrm{g} / 0,0625 \mathrm{~m}^{2}\right)\end{array}$} & \multirow{2}{*}{$\frac{M g \cdot h a^{3}}{4,43}$} & \multirow{2}{*}{$\frac{C / N}{22}$} \\
\hline & 27,71 & $a$ & & & & \\
\hline 126 & 30,14 & $a$ & & & 4,82 & 24 \\
\hline 137 & 35,68 & $a$ & $b$ & & 5,71 & 25 \\
\hline 119 & 40,49 & $a$ & $b$ & & 6,48 & 32 \\
\hline 38 & 44,78 & $a$ & $b$ & $c$ & 7,16 & 26 \\
\hline 16 & 45,28 & $a$ & $b$ & $c$ & 7,24 & 22 \\
\hline 68 & 45,75 & $a$ & $b$ & c & 7,32 & 27 \\
\hline 44 & 46,88 & $a$ & $b$ & c & 7,50 & 24 \\
\hline 98 & 47,13 & $a$ & $b$ & c & 7,54 & 23 \\
\hline 91 & 47,63 & $a$ & $b$ & c & 7,62 & 19 \\
\hline 136 & 48,11 & a & $b$ & c & 7,70 & 22 \\
\hline 5 & 49,11 & $a$ & $b$ & c & 7,86 & 30 \\
\hline 8 & 50,41 & $a$ & $b$ & c & 8,07 & 24 \\
\hline 139 & 55,58 & $a$ & $b$ & c & 8,89 & 42 \\
\hline 66 & 57,28 & $a$ & $b$ & c & 9,16 & 57 \\
\hline 97 & 66,95 & $a$ & $b$ & c & 10,71 & 23 \\
\hline 36 & 74,00 & & $b$ & $c$ & 11,84 & 23 \\
\hline 147 & 85,68 & & & c & 13,71 & 27 \\
\hline Significancia & $\ldots$ & 0,111 & 0,123 & 0,061 & $\ldots$ & $\ldots$ \\
\hline Média & 49,92 & $\ldots$ & $\ldots$ & $\ldots$ & 7,99 & 27. \\
\hline$s^{2}(I)$ & $\ldots$ & $\ldots$ & $\ldots$ & $\ldots$ & 5,3 & 81,0 \\
\hline$s^{(2)}$ & $\ldots$ & $\ldots$ & $\ldots$ & $\ldots$ & 2,3 & 9,0 \\
\hline$s_{x}^{(3)}$ & $\ldots$ & ... & $\ldots$ & $\ldots$ & 1,6 & 5,7 \\
\hline$C V(\%)^{(4)}$ & $\ldots$ & $\ldots$ & $\ldots$ & ... & 28,8 & 34,6 \\
\hline
\end{tabular}

Unidades amostrais primárias com médias não ligadas por mesma letra diferem pelo teste de Student Neuman Keul's - SNK a 5\% de probabilidade.

Nota: (1) Variância; (2) Desvio-padrão; (3) Erro-padrão; (4) Coeficiente de variação.

Há várias hipóteses sobre as diferenças existentes entre a quantidade de serapilheira e as UAPs. Uma delas pode ser devido à correlação entre a serapilheira e a produção de biomassa. A Figura 4 mostra que não houve tendência entre a biomassa de serapilheira acumulada e a produção de biomassa de folhas. Para as demais variáveis, também não foi observada correlação com tendência. A correlação (r) entre a biomassa de serapilheira acumulada e a produção de biomassa de madeira foi de -0,28; da casca $(-0,25)$; dos galhos $(-0,18)$; da miscelânea $(-0,26)$ e total $(-0,27)$.

Outra hipótese sobre a menor quantidade de serapilheira nas unidades 120 e 126, bem como sobre as diferenças entre as 18 UAPs pode ser devido ao número de árvores presentes, o diâmetro e a altura das espécies (CALDEIRA, 2003; WATZLAWICK, 2003). Mas, provavelmente, esses fatores não tenham influenciado no acúmulo de serapilheira, pois foram encontradas 5 e 18 espécies nas unidades 120 e 126, 
respectivamente. Na unidade com maior acúmulo de serapilheira foram encontradas 8 espécies. Em relação ao diâmetro e altura média das unidades, foram encontrados na unidade 120 , DAP de 22,4 cm e altura 15,3 m, e na unidade 126, DAP $23,1 \mathrm{~cm}$ e altura de $11,8 \mathrm{~m}$. Na unidade com maior acúmulo de serapilheira, o DAP e altura foram de $17,5 \mathrm{~cm}$ e $13,0 \mathrm{~m}$, respectivamente.

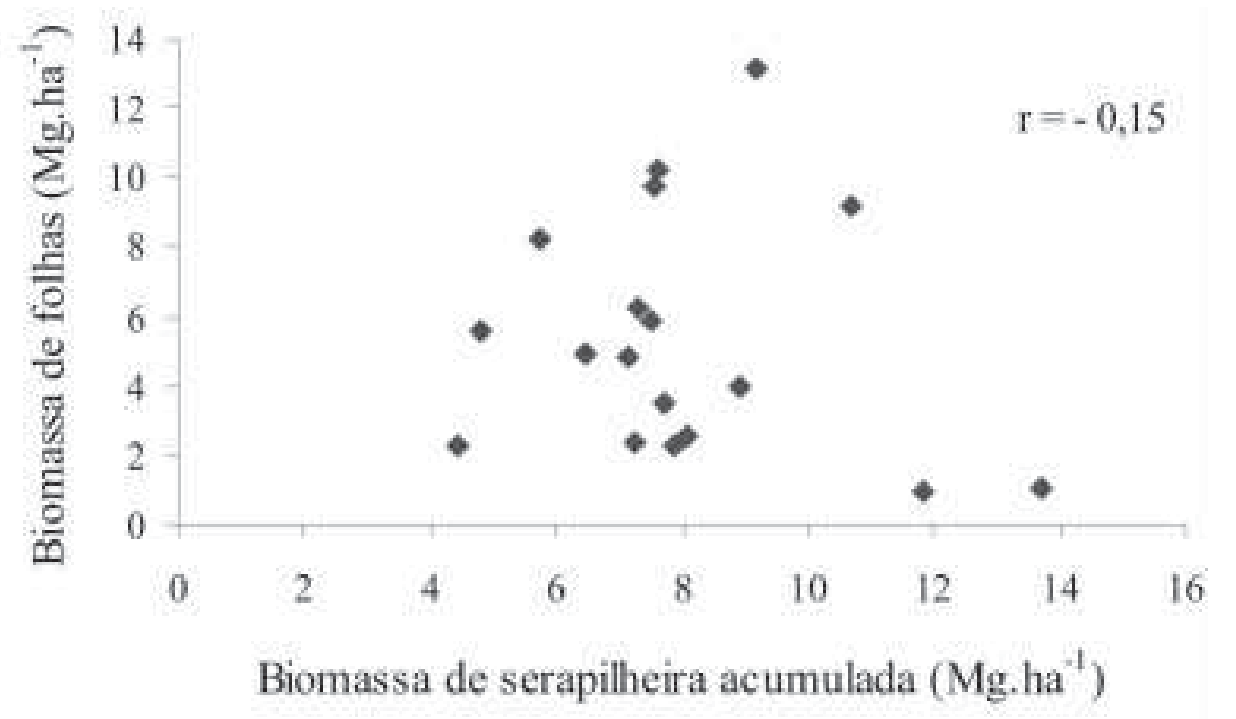
FIGURA 4 - Correlação entre a biomassa de serapilheira acumulada e a biomassa de folhas na Floresta Ombrófila Mista Montana, General Carneiro (PR)

Figure 4 - Correlation between accumulate litter biomass and leaves biomass of "Ombrofila Mista Montana” Forest, General Carneiro (PR)

As diferenças entre as menores e maiores quantidades de biomassa de serapilheira acumulada nas unidades 120,126 e 147 também podem ser devido o estádio sucessional da floresta. Das 18 UAPs, 66,7\%, estavam no estádio sucessional capoeirão e 33,3\% na floresta secundária avançada (FIGURA 3). No entanto, nesse estudo, foi observado que não houve tendência de correlação definida entre a biomassa de serapilheira acumulada e o estádio sucessional observado na floresta, ou seja, a correlação entre essas variáveis foi 0,21 . Alguns estudos mostram que existe correlação entre a serapilheira acumulada e o estádio sucessional como, por exemplo, Brun et al. (2001), que observaram uma correlação expressiva entre a quantidade de serapilheira acumulada nas três fazes sucessionais (capoeirão com 27 anos de idade, floresta secundária com 45 a 50 anos de idade e floresta madura) em Floresta Estacional Decidual, no Rio Grande do Sul.

Estudo feito por Britez (1994) em duas florestas da planície litorânea da Ilha do Mel, em Paranaguá - PR, mostra que, no estádio inicial, a serapilheira acumulada é descontínua, sendo que existem áreas com ausência total dessa, ficando o solo mineral completamente exposto. Nos outros estádios, a serapilheira acumulada é mais espessa e contínua, não havendo exposição do solo mineral. As características descritas no estádio inicial acarretam conseqüências, como maior lixiviação dos nutrientes do solo, menor umidade e conseqüentemente uma decomposição mais lenta da matéria orgânica, interferindo, assim, na liberação dos nutrientes. 
A periodicidade na queda das folhas também pode ter influenciado nas diferenças de serapilheira acumulada nas UAPs. A maioria das espécies amostrada era perenifólias, semidecíduas ou decíduas. Na unidade 147, 62,5\% das espécies amostradas eram perenifólias e 25\% semidecíduas. Em ordem decrescente, a maioria das espécies amostrada na unidade 126 era: semidecíduas $>$ perenifólias $>$ decíduas e na 120 perenifólias > semidecíduas > decíduas.

Diferenças estatísticas de serapilheira acumulada entre as UAPs provavelmente estão associadas à qualidade do material produzido pelas espécies, que determinam a sua degradabilidade e talvez as condições ecofisiológicas que proporcionariam menores taxas de decomposição.

O acúmulo de serapilheira na superfície do solo é regulado pela quantidade de material que cai da parte aérea das plantas e sua taxa de decomposição. Esse acúmulo, conforme Pritchett (1990), devese à quantidade anual de serapilheira menos a taxa anual de decomposição. O ritmo da queda da serapilheira é uniforme entre as espécies de árvores que crescem em condições similares de clima e solo.

O acúmulo médio de serapilheira na Floresta Ombrófila Mista Montana foi de 7,99 Mg.ha-1, ou seja, 2,8\% em relação à biomassa total que foi de 280,73 Mg.ha- ${ }^{-1}$. Conforme Rodríguez Jiménez (1988), a produção total de biomassa da Floresta Tropical Pluvial em Buenaventura, Colômbia, foi de 330,8 $\mathrm{Mg} \cdot \mathrm{ha}^{-1} \mathrm{e}$, desse total, 12,9\% era de serapilheira acumulada (42,7 Mg.ha' $\left.\mathrm{M}^{-1}\right)$.

Comparando-se os resultados da serapilheira acumulada da floresta em estudo (7,99 Mg.ha-1 $)$ com os da Floresta Tropical Úmida Baixo Montana, Rio de Janeiro (20,5 Mg.ha ${ }^{-1}$ ), observa-se expressiva diferença entre eles, sendo que esse último se situa entre os maiores valores até agora encontrados na literatura. Por sua vez, os valores elevados de biomassa de serapilheira, conforme Clevelario Júnior (1996), estão associados a tempos de renovação altos, apresentados geralmente por florestas oligotróficas, como a Floresta Tropical Úmida Baixo Montana. Nas florestas com maior escassez de nutrientes, o acúmulo de serapilheira está associado às desacelerações da decomposição e não à queda mais intensa de material formador. Nas florestas onde é maior a escassez de nutrientes, ocorre maior acúmulo de serapilheira, reduzindo a sua velocidade de cilcagem.

Vários fatores influenciaram nas diferenças entre a serapilheira acumulada na floresta do presente estudo e outros tipos de floresta. Toda a dinâmica das reações no material acumulado na superfície do solo é influenciada por fatores do ambiente, temperatura e umidade, pela qualidade inicial do material formador como, por exemplo, relação C/N (TABELA 1), pelos componentes orgânicos, pela lignina e polifenóis, pelos macronutrientes e, em condições especiais, micronutrientes; pelos organismos do solo, como fauna, actnomicetos e bactérias entre outros (O'CONNELLE E SANKARAN (1997); WEDDERBURN; CARTER, 1999).

A serapilheira acumulada nos solos florestais, segundo O’Connelle e Sankaran (1997), pode variar significativamente entre diferentes espécies estabelecidas no mesmo sítio. Outros fatores podem influenciar, tais como baixo nível de nutrientes na serapilheira e no solo, condições desfavoráveis para a decomposição, como déficit de água no solo e na serapilheira, pH alto ou baixo, baixa densidade da população de organismos decompositores, além da época de coleta, bem como da estação do ano.

Existem poucos dados sobre acúmulo de serapilheira em florestas tropicais naturais. Conforme O'Connelle e Sankaran (1997), em determinados locais da América do Sul, a biomassa da serapilheira acumulada de florestas tropicais naturais varia entre 3,1 e 16,5 $\mathrm{Mg} \mathrm{ha}^{-1}$. O valor máximo é observado nas Florestas Submontanas, na Colômbia. Florestas Montanas geralmente acumulam mais serapilheira do que outras florestas tropicais naturais (TANNER, 1980). Isso se deve, provavelmente, em função do baixo teor de nutrientes nas folhas e principalmente devido aos fatores climáticos, os quais resultam numa decomposição lenta.

Nas florestas ombrófilas da Austrália, a serapilheira acumulada pode variar de 4,4 a 6,3 Mg.ha-1 (SPAIN, 1984). De acordo com a revisão realizada por O'Connelle; Sankaran (1997), mais de 75\% dos valores da serapilheira acumulada em florestas tropicais naturais está abaixo de 7,0 Mg.ha-1, tendo como média 6,0 Mg.ha- ${ }^{-1}$.

Qualquer que seja o motivo que tenha provocado as diferenças na serapilheira acumulada entre as UAPs, os processos de queda de folhas melhoram a fertilidade da camada superficial do solo, estabelecendo uma relação $\mathrm{C} / \mathrm{N}$ e um pH mais favorável ao desenvolvimento biótico (MAGALHÃES; BLUM, 1999; NOVAIS; POGGIANI, 1983). 
O acúmulo de serapilheira encontrado na floresta do presente estudo apresenta alguns resultados similares a outros tipos de floresta, conforme mostra a Tabela 2 , apesar das grandes diferenças entre as metodologias utilizadas.

TABELA 2 - Serapilheira acumulada em algumas florestas do mundo Table 2 - Accumulated litter in some forests of the world

\begin{tabular}{|c|c|c|}
\hline Tipo de floresta & Local & Serapilheira $\left(\mathrm{Mg} \mathrm{ha}^{-1}\right)$ \\
\hline \multirow{3}{*}{ 'Floresta Tropical (área montanhosa) } & Porto Rico & 8,1 \\
\hline & Nova Guiné & 7,7 \\
\hline & Missouri, USA & 8.2 \\
\hline \multirow[t]{2}{*}{ 'Floresta Decidua (clima temperado) } & Tenessee, USA & 7,6 \\
\hline & Minesota, USA & 8,4 \\
\hline 'Floresta Tropical (terras baixas) & Nova Guiné & 8,2 \\
\hline${ }^{2}$ Floresta Tropical (climax) & Araras, SP & 8,2 \\
\hline${ }^{3}$ Floresta Tropical Umida & Borneo, Malásia & 8,5 \\
\hline${ }^{4}$ Floresta Ombrófila Mista (tipo floresta I) ${ }^{(1)}$ & & 9,7 \\
\hline${ }^{4}$ Floresta Ombrófila Mista (tipo floresta II) ${ }^{(2)}$ & Caçador, SC & 7,5 \\
\hline${ }^{5}$ Floresta Ombrófila Mista Montana (estádio I) ${ }^{(3)}$ & & 7,9 \\
\hline Floresta Ombrófila Mista Montana (estádio II) ${ }^{(4)}$ & General Carneiro, PR & 8,6 \\
\hline${ }^{5}$ Floresta Ombrófila Mista Montana (estádio III) ${ }^{(5)}$ & & 7,6 \\
\hline
\end{tabular}

Fonte: ${ }^{1}$ Sutton, Whitmore e Chadwick (1983), apud Anderson e Swift (1983).

${ }^{2}$ Morellato (1992).

${ }^{3}$ Proctor (1983).

${ }^{4}$ Floss, Caldato e Bohner (1999).

${ }^{5}$ Sanquetta et al. (2002), apud Watzlawick (2002)

Nota: (1) Predominância de Araucaria angustifolia no estrato superior; (2) Local onde a diversidade de espécies é maior, com predominância de outras espécies no estrato superior; (3) Estádio inicial; (4) Estádio intermediário; (5) Estádio avançado.

\section{Análise estatística das amostras de serapilheira acumulada}

A média da serapilheira acumulada foi de 49,92 g/0,0625 $\mathrm{m}^{2}$, com intervalo de confiança de 95\% de probabilidade, apresentando limite inferior de 19,9 e limite superior de 79,9. O coeficiente de variação encontrado foi de $25,8 \%$, sendo que o número de amostras necessárias para obter-se um erro de $10 \%$ da média com $95 \%$ de probabilidade foi de 36 amostras e de 9 amostras para um erro de $20 \%$ da média na mesma probabilidade (TABELA 3). Foi estimada a verdadeira média da serapilheira acumulada na floresta em estudo com $14,2 \%$ de erro e $95 \%$ de probabilidade. 
TABELA 3 - Análise estatística das amostras de serapilheira acumulada, General Carneiro (PR) Table 3 - Statistical analysis of accumulated litter samples, General Carneiro (PR)

\begin{tabular}{lc}
\hline Variáveis estatísticas & Valores \\
\hline Média $(\mathrm{x})$ & $49,92 \mathrm{~g} / 0,0625 \mathrm{~m}^{2}$ \\
Variância $\left(\mathrm{s}^{2}\right)$ & 202,82 \\
Desvio-padrão $(\mathrm{s})$ & 14,24 \\
Erro padrão $(\mathrm{s})$ & 3,36 \\
Erro de amostragem absoluto & $\pm 29,98$ \\
Erro de amostragem relativo & $60,2 \%$ \\
Intervalo de confiança $(\alpha=5 \%)$ & IC $95[19,9 \leq \mu \leq 79,9]=0,95$ \\
Cocficiente de variação $(\mathrm{CV})$ & $28,5 \%$ \\
Intensidade amostral $(10 \%$ de erro) da média e probabilidade de & \\
$95 \% n=t^{2} \cdot \frac{s^{2}}{E^{2}}$ & 36 amostras por UAP \\
Intensidade amostral $(20 \%$ de erro) da média e probabilidade de & \\
$95 \% n=t^{2} \cdot \frac{s^{2}}{E^{2}}$ & 9 amostras por UAP \\
\hline
\end{tabular}

\section{Nutrientes e carbono orgânico na serapilheira acumulada}

A Tabela 4 evidencia que a serapilheira acumulada é a principal via de transferência de N, K e Ca e carbono orgânico para o solo, demonstrando, assim, a importância do material formado da serapilheira no processo de ciclagem biogeoquímica de nutrientes em sítios florestais, principalmente para o N, o K e o Ca (GRUSAK; POMPER, 1999).

A serapilheira é a principal via de transferência de nutrientes, independente de ser acumulada numa floresta natural ou em povoamentos, conforme mostram os trabalhos de Baggio; Carpanezzi (1997) com Mimosa scabrella, Rodrigues Jiménez (1988) com Bosque Pluvial de Terras Baixas, Drumond et al. (1997) com diferentes coberturas florestais, Clevelario Júnior (1996) em uma Floresta Tropical Úmida Baixo Montanto, Froufe et al. (1998) com Eucalyptus grandis e Albizia guachapele cultivados em sistemas puros e consorciados, Pagano e Durigan (2000) com Mata Ciliar e Schumacher et al. (2002a; 2002b) com Araucaria angustifolia.

TABELA 4 - Teores e conteúdos médios de macronutrientes e carbono orgânico na serapilheira acumulada, General Carneiro (PR)

Table 4 - Content and average matter of macronutrients and organic carbon in accumulated litter in General Carneiro (PR)

\begin{tabular}{lrr}
\hline Carbono/nutriente & Teor $\left(\mathrm{g} \cdot \mathrm{kg}^{-1}\right)$ & Conteúdo $\left(\mathrm{kg}^{-\mathrm{ha}}{ }^{-1}\right)$ \\
\hline $\mathrm{C}$ & 379,20 & $3.029,80$ \\
$\mathrm{~N}$ & 11,97 & 95,66 \\
$\mathrm{P}$ & 0,68 & 5,43 \\
$\mathrm{~K}$ & 5,67 & 45,32 \\
$\mathrm{Ca}$ & 4,61 & 36,84 \\
$\mathrm{Mg}$ & 0,95 & 7,56 \\
$\mathrm{~S}$ & 1,85 & 14,75 \\
\hline
\end{tabular}


Analisando-se os teores de macronutrientes da serapilheira acumulada da floresta em estudo, observa-se que $\mathrm{N}, \mathrm{Ca}$ e $\mathrm{Mg}$ apresentaram valores menores e $\mathrm{P}$ e K valores altos, em relação à serapilheira acumulada da Mata Salão Dourado e da Mata Bombaça (DRUMOND, 1996).

Diferentes teores, bem como conteúdos, de macronutrientes na serapilheira acumulada podem estar relacionados à mobilidade dos biolementos dentro da planta, por exemplo, o K, tornandoo sujeito à lixiviação. A alta variabilidade dos teores de K na serapilheira, segundo Neves (2000) e Pagano e Durigan (2000), entre as épocas de avaliação, guarda relação com a variação da precipitação pluviométrica, o que se explica pela sua alta suscetibilidade à lixiviação via lavagem de folhas e de serapilheira, que decorrem do fato de o K não participar de compostos orgânicos, ocorrendo na forma solúvel ou adsorvido no suco celular (MARSCHNER, 1997). A ciclagem do K na relação solo-planta é mais rápida do que a de outros nutrientes, por se tratar de um cátion monovalente (JORDAN, 1985). No entanto, macronutrientes como $\mathrm{Ca}, \mathrm{Mg}$ e $\mathrm{S}$, embora considerados como moderadamente laváveis, segundo Tukey Júnior e Tukey, citados por Pagano e Durigan (2000), mostram amplitudes de variação dos teores bem menores.

Considerando somente os macronutrientes, o Ca apresentou o terceiro maior teor e conteúdo na serapilheira acumulada, fato esse que pode estar relacionado com a sua pouca mobilidade nos tecidos vegetais e com a longevidade das folhas. Nesse sentido, espera-se que quanto mais velha for a folha, maior será o seu teor de Ca. A baixa mobilidade desse macronutriente dentro dos tecidos vegetais é citada como um fator que determina que a sua maior quantidade de ciclagem na natureza seja feita pela queda e decomposição dos tecidos vegetais senescentes (NILSSON et al., 1995).

Os baixos teores de $\mathrm{K}$ na serapilheira acumulada estão relacionados com suas pequenas taxas na ciclagem biogeoquímica, contrariamente às de $\mathrm{Ca}$, nutriente cujos teores na serapilheira acumulada são muitas vezes superiores aos existentes nos componentes da biomassa acima do solo. A ciclagem biogeoquímica, de modo geral, é a via pela qual os nutrientes de baixa mobilidade na planta são ciclados, uma vez que para esses nutrientes a ciclagem bioquímica torna-se pouca expressiva, contrariamente ao que ocorre para nutrientes de alta mobilidade na planta.

Com a finalidade de estudar melhor o padrão de ciclagem de nutrientes, Nilsson et al. (1995) mostraram que principalmente $\mathrm{Ke} \mathrm{Mg}$, dependendo da capacidade de suporte do substrato, são preferencialmente redistribuídos no interior da planta, ratificando seus baixos teores observados nesse estudo.

De forma geral, pode-se dizer que o conjunto de nutrientes disponíveis na serapilheira acumulada, bem como no solo, representa o total dos nutrientes que serão acessíveis para a vegetação do ecossistema. Nesse contexto, esses reservatórios representam uma porção de nutrientes que circulam no ecossistema e sobre a qual a vegetação exerce uma participação direta, pois os componentes não se encontram fixados na biomassa viva.

\section{Micronutrientes na serapilheira acumulada}

A Tabela 5 mostra que a serapilheira acumulada das espécies estudadas foi a principal via de transferência de Fe, Mn e Zn para o solo, demonstrando a importância do material formado da serapilheira no processo de ciclagem biogeoquímica de nutrientes em sítios florestais.

Os teores e os conteúdos de micronutrientes na serapilheira acumulada apresentaram a seguinte ordem: $\mathrm{Fe}>\mathrm{Mn}>\mathrm{Zn}>\mathrm{B}>\mathrm{Cu}$. Os maiores teores e conteúdos, principalmente de Fe e $\mathrm{Zn}$ na serapilheira acumulada, podem ser justificados pela sua mobilidade e, conseqüentemente, pelos seus maiores teores nas folhas de algumas espécies, bem como teores médios maiores nas folhas da floresta em relação à madeira, casca e galhos, conforme a Tabela 5. Outra justificativa pode ser a contaminação com o solo, ou seja, amostras de serapilheira com solo. 
TABELA 5 - Teores e conteúdos médios de micronutrientes na serapilheira acumulada, General Carneiro (PR)

Table 5 - Content and average matter of micronutrients in accumulated litter in General Carneiro (PR)

\begin{tabular}{lrr}
\hline Micronutriente & \multicolumn{1}{c}{ Serapilheira Acumulada } \\
\hline $\mathrm{B}$ & Teor $\left(\mathrm{mg}^{\mathrm{kg}} \mathrm{kg}^{-1}\right)$ & Conteúdo $\left(\mathrm{kg} \cdot \mathrm{ha}^{-1}\right)$ \\
$\mathrm{Cu}$ & 27,26 & 0,22 \\
$\mathrm{Fé}$ & 18,72 & 0,15 \\
$\mathrm{Mn}$ & $3,415,44$ & 27,29 \\
$\mathrm{Zn}$ & 865,94 & 6,92 \\
& 42,35 & 0,34 \\
\hline
\end{tabular}

Rodrígues Jiménez (1988), em um Bosque Pluvial de Terras Baixas na Colômbia, e Schumacher et al. (2002a), em plantios de Araucaria angustifolia com 14 anos de idade, também constataram que a serapilheira acumulada foi a principal via de transferência de Fe, Mn e Zn para o solo.

$\mathrm{O}$ B é o quarto micronutriente em teor e, conseqüentemente, em conteúdo na serapilheira acumulada, sendo que esse fato pode estar relacionado com a sua pouca mobilidade nos tecidos vegetais. Desse modo, é de se esperar que quanto mais velha a folha, maior o teor de B (JONES JÚNIOR, 1970). A mobilidade intermediária do B dentro dos tecidos vegetais pode ser um dos fatores determinantes para que a maior intensidade de sua ciclagem na natureza seja resultante da queda e decomposição dos tecidos vegetais senescentes.

O B possui mobilidade intermediária no floema, de acordo com Marschner (1997), mas, segundo Brown e Hu (1998) e Yamada (2000), o B é imóvel no floema. No entanto, atualmente, esse micronutriente é considerado como móvel no floema de todas as espécies (amendoeiras, macieira e nectarinas) que utilizam polióis, ou seja, complexos de açúcares simples com álcool, como, por exemplo, sorbitol, manitole dulcitol como um metabólito fotossintético primário (BROWN; HU, 1998; YAMADA, 2000).

\section{CONCLUSÕES}

O acúmulo médio de serapilheira na Floresta Ombrófila Mista Montana foi de 7,99 Mg.ha-1, ou seja, 2,8\% em relação à biomassa total, que foi de 280,73 Mg.ha'

Houve diferença estatística na produção de serapilheira acumulada entre as unidades amostrais primárias.

A serapilheira acumulada foi uma importante via de transferência de carbono orgânico, de macronutrientes ( $\mathrm{N}, \mathrm{K}$ e $\mathrm{Ca}$ ) e micronutrientes (Fe, Mn e $\mathrm{Zn}$ ) para o solo.

No que se refere à relação $\mathrm{C} / \mathrm{N}$, houve diferença em cada unidade amostral primária (UAP). A relação $\mathrm{C} / \mathrm{N}$ média para a floresta em estudo foi de 27. 


\section{REFERÊNCIAS}

ANDERSON, J. M.; SWIFT, M. J. Decomposition in tropical forests. In: SUTTON, S. L.; WHITMORE, T. C.; CHADWICK, A. C. (Ed.). Tropical rain forest: ecology and management. London: Blackwell Scientific, 1983. p. 287-309.

BAGGIO, A. J.; CARPANEZZI, A. A. Estoque de nutrientes nos resíduos da exploração de bracatingais. Boletim de Pesquisa Florestal, Colombo, n. 34, p. 17-29, jan./jun., 1997.

BOLETIM DE PESQUISA. Levantamento de reconhecimento dos solos do Estado do Paraná. Londrina: [s. n.], n. 27, t. 1 e 2, 1984.

BRAY, J. R.; GORHAM, E. Litter production in the forests of the world. Advances in ecological research, New York, v. 2, p. 101-157, 1964.

BRITEZ, R. M. Cicalgem de nutrientes em duas florestas da planície litorânea da Ilha do Mel, Paranaguá, PR. 1994. 240 f. Dissertação (Mestrado em Agronomia) - Setor de Ciências Agrárias, Universidade Federal do Paraná, Curitiba, 1994.

BROWN, P. H.; HU, H. Manejo do boro de acordo com sua mobilidade nas diferentes culturas. POTAFOS: informações agronômicas, Piracicaba, n. 84, p. 1-4, 1998.

BRUN, E. J. et al. Decomposição da serapilheira produzida em três fases sucessionais de floresta estacional decidual no RS. In: SIMPÓSIO DE PÓS-GRADUAÇÃO EM ENGENHARIA FLORESTAL, 1., 2001. Anais... Santa Maria: UFSM, 2001. 1 CD ROM.

CALDEIRA, M. V. W. Determinação de biomassa e nutrientes em uma Floresta Ombrófila Mista Montana em General Carneiro, Paraná. 2003. 176 f. Tese (Doutorado em Ciências Florestais) - Setor de Ciências Agrárias, Universidade Federal do Paraná, Curitiba, 2003.

CAMARGO, J. B. Geografia física, humana e econômica do Paraná. 2. ed. Chichetec: [s.n.], 1998. $207 \mathrm{p}$.

CARPANEZZI, A. A. Banco de sementes e deposição de folhedo e seus nutrientes em povoamentos de bracatinga (Mimosa scabrella Bentham) na região metropolitana de CuritibaPR. 1997. 177 f. Tese (Doutorado em Ciências Biológicas) - Instituto de Biociências, Universidade Estadual Paulista, Rio Claro, 1997.

CLEVELARIO JÚNIOR, J. Distribuição de carbono e de elementos minerais em um ecossistema florestal tropical úmido baixo-montana. 1996. 135 f. Tese (Doutorado em Solos e Nutrição de Plantas) - Universidade Federal de Viçosa, Viçosa, 1996.

DRUMOND, M. A. Alterações fitossociológicas e edáficas decorrentes de modificações da cobertura vegetal na Mata Atlântica, região do médio Rio Doce, MG. 1996. 73 f. Tese (Doutorado em Ciência do Solo) - Universidade Federal de Viçosa, Viçosa, 1996.

DRUMOND, M. A. et al. Distribuição de biomassa e de nutrientes em diferentes coberturas florestais e pastagem na região do médio Rio Doce-MG. Revista Árvore, Minas Gerais, v. 21, n. 2, p. 187-199, 1997.

FLOSS, P. A.; CALDATO, S. L.; BOHNER, J. A. M. Produção e decomposição de serapilheira na Floresta Ombrófila Mista da reserva florestal da EPAGRI/EMBRAPA de Caçador, SC. Revista Agropecuária Catarinense, Florianópolis, v. 12, n. 2, p. 19-22, 1999.

FROUFE, L. C. M. et al. Reciclagem de nutrientes via folhas - serapilheira de Eucalyptus grandis e Albiz̨ia guachapele cultivados em sistemas puros e consorciados. FERTBIO 98: interrelação fertilidade, biologia do solo e nutrição de plantas: consolidando um paradigma, 1998, Caxambu. Resumos... Caxambu: UFLA, p. 559. 
GARAY, I.; ANDRADE, F. N.; KINDEL, A. Evolução da serapilheira e da fertilidade do solo em região de Mata Atlântica de tabuleiros: de plantios a mata nativa. In: CONGRESSO DE ECOLOGIA: ambiente e sociedade, 5., 2001. Porto Alegre. Resumos... Porto Alegre: UFRGS/Centro de Ecologia, 2001. p. 242.

GRUSAK, M. A.; POMPER, K. W. Influence of pod stomatal density and pod transpiration on the calcium concentrations of snap bean pods. Journal American Society Horticulture Science, v. 124, n. 2, p. 194-198, 1999.

IAPAR. Cartas climáticas básicas do Estado do Paraná. Londrina: IAPAR, 1994. 49 p. (Documentos; 18).

IBGE. Manual técnico da vegetação brasileira. Rio de Janeiro: IBGE, 1992. 92 p.

JONES JÚNIOR, J. B. Distribution if 15 elements in corn leaves. Communications in Soil Science and Plant Analysis, New York, v. 1, p. 27-34, 1970.

JORDAN, C. F. Nutrient cycling in tropical forest ecosystems. New York: John Wile, 1985. 190 p.

MAGALHÃES, L. M. S.; BLUM, W. E. H. Concentração e distribuição de nutrientes nas folhas de espécies florestais, na Amazônia Ocidental. Floresta e Ambiente, Seropédica, v. 6, n. 1, p. 127-137, jan./dez., 1999.

MARSCHNER, H. Mineral nutrition of higher pants. 2. ed. San Diego: Academic, 1997. 889 p.

MIYAZAWA, M. et al. Análises químicas de tecido vegetal. In: SILVA, F. C. (Ed.). Manual de análises químicas de solos, plantas e fertilizantes. Brasília: EMBRAPA Solos, 1999. p. 171-223. (Comunicação para Transferência de Tecnologia).

MORELLATO, L. P. C. Nutrient cycling in two south-east Brasilian forest. I Litterfall and litter standing crop. Journal of Tropical Ecology, Cambridge, v. 8, p. 205-215, 1992.

NEVES, J. C. L. Produção e participação de biomassa, aspectos nutricionais e hídricos em plantios clonais de eucalipto na região litorânea do Espírito Santo. 2000. 191 f. Tese (Doutorado em Produção Vegetal) - Universidade Estadual do Norte Fluminense, Rio de Janeiro, 2000.

NILSSON, L. O. et al. Nutrient uptake and cycling in forest ecosystems - present status and future research directions. Plant and Soil, The Hague, v. 168/169, p. 5-13, 1995.

NOVAIS, R. F.; POGGIANI, F. Deposição de folhas e nutrientes em plantações florestais puras e consorciadas de Pinus e Liquidambar. Revista IPEF, Piracicaba, v. 23, p. 57-60, 1983.

O'CONNELL, A. M.; SANKARAN, K. V. Organic matter accretion, decomposition and mineralisation. In: NAMBIAR, E. K. S., BROWN, A. G. (Ed.). Management of soil, nutrients and water in tropical plantations forests. Canberra: ACIAR Australia/CSIRO, 1997. p. 443-480. (Monograph; n. 43).

PAGANO, S. N.; DURIGAN, G. Aspectos da ciclagem de nutrientes em matas ciliares do oeste do estado de São Paulo, Brasil. In: RODRIGUES, R. R. LEITÃO FILHO, H. F. (Ed.). Matas ciliares: conservação e recuperação. São Paulo: EDUSP/FAPESP, 2000. p. 109-123.

PARANÁ. Secretária de Estado de Agricultura e Abastecimento, Instituto de Terras, Cartografia e Florestas. Atlas do Estado do Paraná, Curitiba, 1987. 73 p.

PRITCHETT, W. L. Suelos forestales: propriedades, conservación y majoramiento. Mexico: John Wiley \& Sons, Inc., 1990. 634 p.

PROCTOR, J. Tropical forest litterfall. I. Problems of data comparison. In: SUTTON, S. L.; WHITMORE, T. C.; CHADWICK (Ed.). Tropical Rain Forest: Ecology and Management. Oxford: Blackwell Scientific Publications, v. 2, p. 267-273, 1983. 
RODRÍGUEZ JIMÉNEZ, L. V. A. Consideraciones sobre la biomasa, composición química y dinámica del bosque pluvial tropical de colinas bajas. Bajo Calima Buenaventura, Colombia. Corporación Nacional de Investigación y Fomento Forestal, Bogotá: 1988. 36 p. (Serie Documentación; n.16).

SANTOS, V. D. Ciclagem de nutrientes minerais em mata tropical subcaducifolia dos planaltos do Paraná (Parque Estadual Vila Rica do Espírito Santo - Fênix/PR). 1989. 387 f. Tese (Doutorado em Ecologia e Recursos Naturais) - Universidade Federal de São Carlos, São Carlos, 1989.

SCHUMACHER, M. V. et al. A. Quantifizierung der biomasse und des nährstoffgehalts bei der erstdurchforstung eines araukarienbestandes in Quedas do Iguaçu (Paraná, Brasilien). Forstarchiv, Hannover, v. 73, n. 5, p. 187-194, 2002a.

et al. Quantificação da biomassa e do conteúdo de nutrientes no corte raso de uma floresta de Araucaria angustifolia (Bert.) O. Ktze. na região de Quedas de Iguaçu-PR. Santa Maria: UFSM, 2002b. (Relatório de pesquisa).

SPAIN, A. V. Litterfall and the standing crop litter in three tropical Australian rainforests. The Journal of Ecology, Oxford, v. 72, p. 947-961, 1984.

STEEL, R. G. D.; TORRIE, J. H. Principles and procedures of statistics: with special reference to the biological sciences. New York: McGraw Hill, 1960. 481 p.

SYERS, J. K.; CRASWELL, E. T. Role of soil organic matter in sustainable agricultural systems. In: LEFROY, R. D. B.; BLAIR, G. J.; CRASWELL, E. T. (Ed.). Soil organic matter management for sustainable agriculture. Canberra: ACIAR, 1995. p. 7-14.

TALORA, D. C.; MORELLATO, P. C. Fenologia de espécies arbóreas em floresta de planície litorânea do sudeste do Brasil. Revista Brasileira de Botânica, São Paulo, v. 23, n. 1, p. 13-26, 2000.

TANNER, E. V. J. Litterfall in montane rain forests of Jamaica and its relation to climate. Journal of Ecology, v. 68, p. 833-848. 1980.

TEDESCO, M. J. et al. Análise de solos, plantas e outros materiais. Porto Alegre: UFRG, Departamento de Solos/Faculdade de Agronomia, 1995. 174 p. (Boletim Técnico; 5).

VITOUSEK, P. M. Litterfall, nutrient cycling and nutrient limitation in tropical forests. Ecology, Durham, v. 65, n. 1, p. 258-298, 1984.

WATZLAWICK, L. F. Estimativa de biomassa e carbono em floresta ombrófila mista e plantações florestais a partir de dados de imagens do satélite IKONOS II. 2003. 120 f. Tese (Doutorado em Ciências Florestais) - Setor de Ciências Agrárias, Universidade Federal do Paraná, Curitiba, 2003.

WATZLAWICK, L. F. et al. Fixação de carbono em Floresta Ombrófila Mista em diferentes estágios sucessionais. In: SANQUETTA, C. R. et al. (Ed.). As florestas e o carbono. Curitiba, 2002. p. 153-173.

WEDDERBURN, M. E.; CARTER, J. Litter decomposition by four functional tree types for use in silvopastoral systems. Soil Biology and Biochemistry, Elmsford, v. 31, p. 455-461, 1999.

WISNIEWSKI, C. et al. Caracterização do ecossistema e estudo das relações solo-cobertura vegetal em planície pleistocênica do litoral paranaense. Curitiba: UFPR/Departamento de Solos, 1997. 55 p. (Projeto Integrado-CNPq, Relatório final).

YAMADA, T. Boro: será que estamos aplicando a dose suficiente para o adequado desenvolvimento das planta? POTAFOS: Informações agronômicas, Piracicaba, n. 90, p. 1-5, 2000.

Recebido em: 02/06/2006

Received in: 06/02/2006

Aprovado em: 30/09/2006

Accepted in: 09/30/2006 